
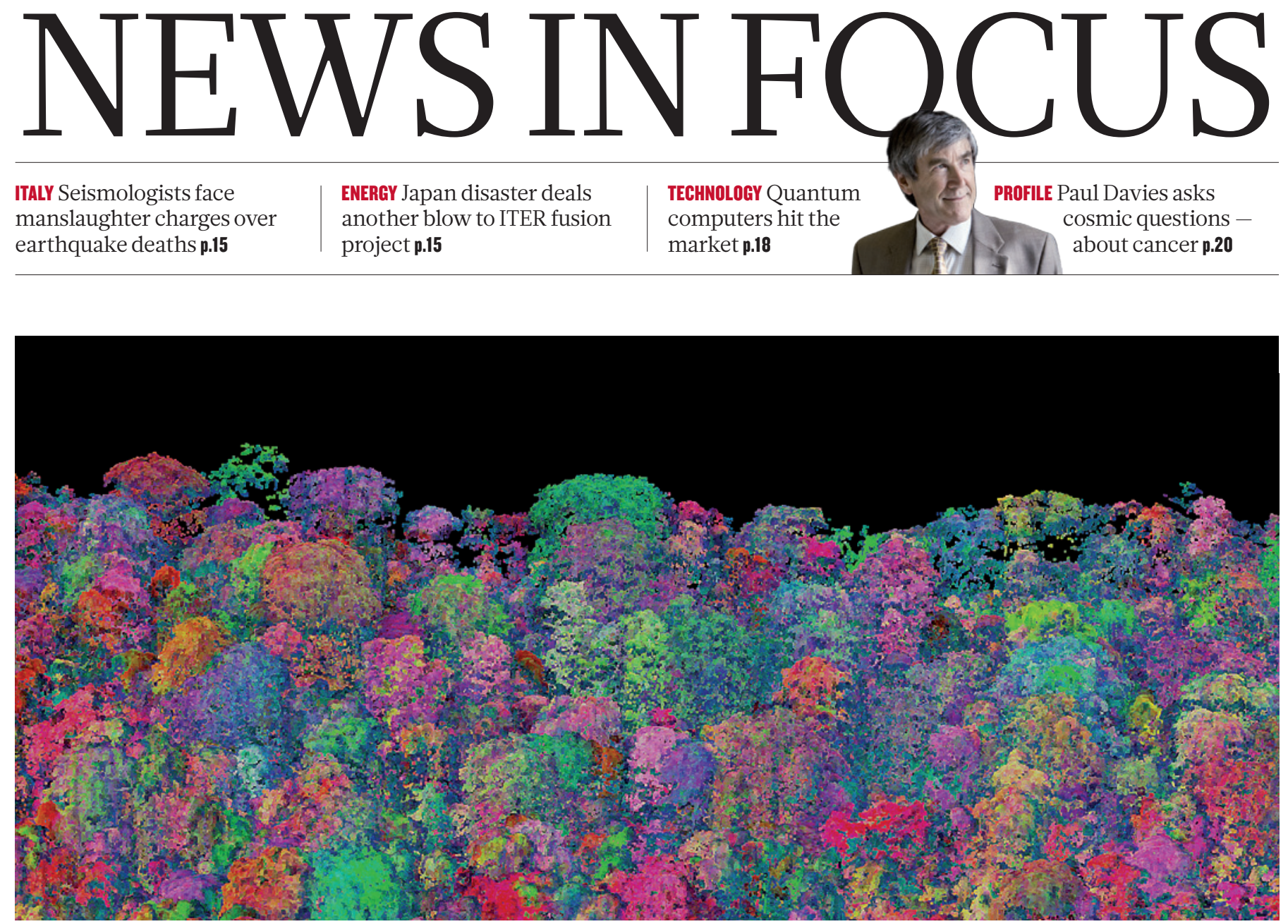

A three-dimensional image of a forest in Panama, based on data from the Carnegie Airborne Observatory. The retooled observatory will be far more sensitive.

\title{
ECOLOGY
}

\section{A new eye on biodiversity}

\section{Airborne observatory will use chemical clues to map and assess tropical ecosystems.}

\section{BY JEFF TOLLEFSON}

$\mathrm{F}$ or tropical ecologist Greg Asner, it's all about seeing the forest through its trees. Over the past two years, he and his team at the Carnegie Institution for Science in Stanford, California, have used world-class tree climbers, bows and arrows, and even shotguns to gather samples of vegetation from forest canopies around the globe. They have created a digital catalogue of the chemical and optical properties of some 4,700 plant species in different conditions. Now comes the moment of truth.

On 2 June, Asner and his team will unveil the latest version of the Carnegie Airborne Observatory (CAO), an aircraft that will combine a state-of-the-art optical sensor with a laser capable of mapping forests in unprecedented threedimensional detail. The system will allow Asner to build on earlier work cataloguing forest

carbon stocks in support of efforts to reduce deforestation (see 'Taking stock of global carbon'), and will significantly advance the team's biodiversity research. With the digital catalogue as a reference, Asner hopes that the observatory will be able to perceive the species of many individual trees by their optical properties, while offering insights into forest health and diversity.

The team's work combines physics, biochemistry and ecology, beginning with measuring subtle differences in the way the forest canopy absorbs and reflects solar radiation. The signal varies depending on the leaves' concentrations of nutrients, minerals, pigments such as chlorophyll, and the compounds that plants use

\section{ONATURE.COM} For more on Greg Asner's work in tropical forests, see: go.nature.com/75goqn to protect themselves against the Sun and predators. In specimens from one region of the Amazon rainforest in southern Peru, Asner and his wife, Robin Martin, identified 21 spectral traits that provided identifying signals for $90 \%$ of the species. "A lot of people look at trees and just see green," says Asner. "I see a kaleidoscope."

The heart of the CAO's US\$8.3-million sensing system - dubbed the Airborne Taxonomic Mapping System (AToMS) - is a spectroscopic imager designed by engineers at NASA's Jet Propulsion Laboratory (JPL) in Pasadena, California. Capable of registering more than 400 frequencies of light, from ultraviolet to infrared, the instrument will take 60,000 measurements per second, with great accuracy. "This really has taken everything we have learned at NASA and brought it to bear in the most advanced airborne imaging spectrometer ever built," says Rob Green, lead engineer on the project at the JPL.

With data from a single flight that used an earlier version of the system, Asner and his colleagues identified more than 30 species. 


\section{BENCHMARK OF BIOMASS}

Map showing the estimated biomass of carbon (top) and the uncertainty in those estimates (bottom).
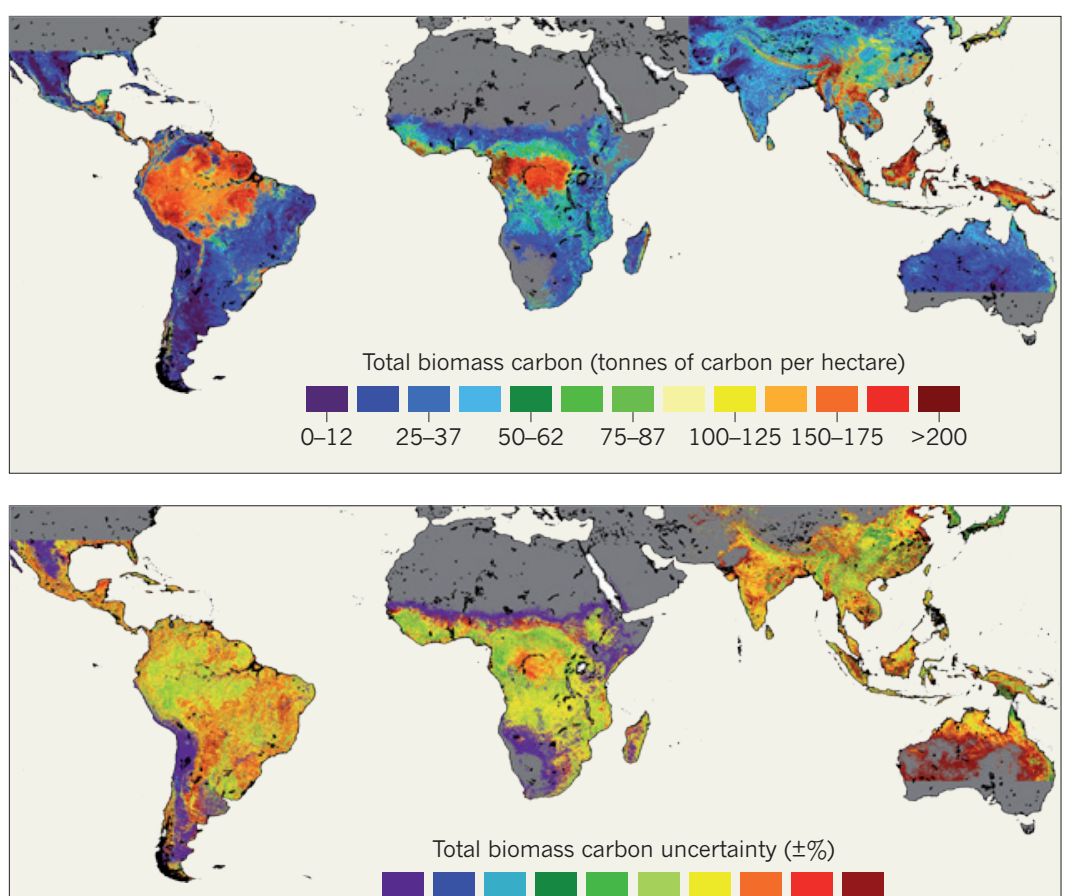

Total biomass carbon uncertainty $( \pm \%)$

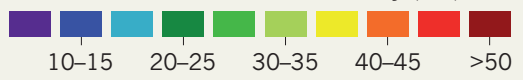

\section{REMOTE SENSING \\ Taking stock of global carbon}

This week, researchers unveiled what they hope will be a benchmark assessment of the carbon stored in the world's tropical forests. The map (pictured), which spans 75 developing countries across tropical regions, shows not only the amount of carbon stored in forests as of the early 2000 s, but also the accuracy of the estimate.

"It's more than a beautiful picture," says Sassan Saatchi, a remote-sensing specialist at NASA's Jet Propulsion Laboratory in Pasadena, California, who led the research. "This is a benchmark that can be used as a basis for comparison in the future."

Forests are normally carbon 'sinks' that take up and store carbon, but logging and natural disturbances can turn them into temporary or permanent carbon sources. Knowing how much they hold and release is crucial for international negotiations that seek to pay developing countries to keep forests standing. But efforts to assess global carbon stocks and how they are changing have been hampered by deficiencies in remote-sensing technologies and a lack of data confirming satellite observations on the ground. Now
Saatchi and his team have developed a methodologically consistent way to combine the available data into a global estimate of carbon stocks.

Focusing on forests in the Southern Hemisphere, in tropical parts of Asia and in central America, the team combined laserbased measurements of forest height from NASA's ICESat mission with other remotesensing data, as well as with information from more than 4,000 ground-level inventories of tree height and biomass. This enabled the team to map forest structure and carbon density down to a resolution of 1 kilometre. The 2.5-billion-hectare study area holds a total of 247 gigatonnes of carbon, the team estimates (S. Saatchi et al. Proc. Natl Acad. Sci USA doi:10.1073/ pnas.1019576108; 2011).

"To have efficient negotiations on the forest contribution in reducing greenhousegas emissions we need improved data," says Sten Nilsson, a forest scientist with the Swedish company Forest Sector Insights and a researcher at the International Institute for Applied Systems Analysis in Laxenburg, Austria. "This work is one contribution in this direction." Quirin Schiermeier
- The latest technology, he says, will be three to six times more sensitive, and should enable the detection of many more plants.

No one can say for certain what the implications of these new data might be, but ecologists - many of whom have spent decades tramping through the jungle in muddy boots - are lining up to find out. "It is going to change a variety of fields of tropical ecology," says Alan Townsend, an ecologist at the University of Colorado at Boulder. "How much and in what ways we don't really know, but there is no doubt that we are starting to walk down a new path."

Peter Vitousek, an ecologist at Stanford University in California, says that he started off with the same mindset as many of his colleagues: suspicion of yet another over-hyped remotesensing technology. On his first collaboration with Asner on a project in Hawaii several years ago, however, Vitousek saw how remote-sensing data could be used to identify invasive species and to tease out relationships among plants. After the aerial data identified areas in which the canopy was unusually depleted of nitrogen, the team went in on the ground and discovered that an invasive ginger plant was competing with native trees for the nutrient. Here was a case in which the spectral data themselves led the researchers to discover an ecological interaction, rather than simply confirming data gathered on the ground, says Vitousek. "I needed to be persuaded that this was really something new, and that persuaded me."

Asner is set to fly the CAO to the Amazon later this month, with a dual research focus. One goal is to survey the rainforest to gauge the impact of last year's drought, which seems to have been even more severe and widespread than that of 2005 - the worst event of its kind for 100 years, and one that scientists are still studying. The other is to fly over plots monitored by the Amazon Forest Inventory Network (RAINFOR) to address a nagging question: how representative are the areas that scientists have been studying for decades?

RAINFOR tracks long-term data on soil and plant growth, but Asner's information will provide unprecedented detail on the chemistry of leaves in the canopy. The ground plots provide a record of how each tree in the area fared through the drought, and Asner's crew should be able to pick those trees out of their broader analysis to look for any lingering effects. "The hypothesis is that those trees that have suffered during the drought also have different canopy chemistry," says Oliver Phillips, an ecologist at the University of Leeds, UK, who coordinates RAINFOR. "It's very exciting," he says. "But we'll see how it pans out."

Asner also has his own agenda, which begins with mapping out tropical biodiversity. "One thing is for sure: the array of chemical traits in these upper canopies is amazing and radically under-appreciated," he says. "We are going to use that to our advantage to get canopy diversity mapped." 